(c) Cambridge University Press 2012. The online version of this article is published within an Open Access environment subject to the conditions of the Creative Commons Attribution-NonCommercial-ShareAlike licence < http://creativecommons.org/licenses/by-nc-sa/3.0/ > . The written permission of Cambridge University Press must be obtained for commercial re-use.

\title{
Nationwide inventory of mosquito biodiversity (Diptera: Culicidae) in Belgium, Europe
}

\author{
V. Versteirt ${ }^{1}$, S. Boyer ${ }^{2}$, D. Damiens ${ }^{2}$, E.M. De Clercq ${ }^{4}$, \\ W. Dekoninck ${ }^{3}$, E. Ducheyne ${ }^{4}$, P. Grootaert ${ }^{3}$, C. Garros ${ }^{2}$, \\ T. Hance ${ }^{2}$, G. Hendrickx ${ }^{4}, M$. Coosemans ${ }^{1,5 *}$ \\ and W. Van Bortel ${ }^{1}$
}

${ }^{1}$ Department of Biomedical Science, Vector Biology Group, Medical Entomology Unit, Institute of Tropical Medicine, Nationalestraat 155, B-2000 Antwerp, Belgium: ${ }^{2}$ Biodiversity research Centre, Earth and Life Institute, Université catholique de Louvain, Place Croix Sud 4/5, B-1348 Louvain-LaNeuve, Belgium: ${ }^{3}$ Department of Entomology, Royal Belgian Institute of Natural Sciences, Vautierstraat 29, B-1000 Brussels, Belgium: ${ }^{4}$ Avia-GIS, Risschotlei 33, B-2980 Zoersel, Belgium: ${ }^{5}$ Department of Biomedical Sciences, Faculty of Pharmaceutical, Veterinary and Biomedical Sciences, University of Antwerp, Universiteitsplein 1, B-261 0 Antwerpen (Wilrijk), Belgium

\begin{abstract}
To advance our restricted knowledge on mosquito biodiversity and distribution in Belgium, a national inventory started in 2007 (MODIRISK) based on a random selection of 936 collection points in three main environmental types: urban, rural and natural areas. Additionally, 64 sites were selected because of the risk of importing a vector or pathogen in these sites. Each site was sampled once between May and October 2007 and once in 2008 using Mosquito Magnet Liberty Plus traps. Diversity in pre-defined habitat types was calculated using three indices. The association between species and environmental types was assessed using a correspondence analysis. Twenty-three mosquito species belonging to traditionally recognized genera were found, including 21 indigenous and two exotic species. Highest species diversity (Simpson 0.765) and species richness (20 species) was observed in natural areas, although urban sites scored also well (Simpson 0.476, 16 species). Four clusters could be distinguished based on the correspondence analysis. The first one is related to human modified landscapes (such as urban, rural and industrial sites). A second is composed of species not associated with a specific habitat type, including the now widely distributed Anopheles plumbeus. A third group includes species commonly found in restored natural or bird migration areas, and a fourth cluster is composed of forest species. Outcomes of this study demonstrate the effectiveness of the designed sampling scheme and support the choice of the trap type. Obtained results of this first country-wide inventory of the Culicidae in Belgium may serve as a basis for risk assessment of emerging mosquito-borne diseases.
\end{abstract}

*Author for correspondence

Fax: + 3232476359

E-mail: mcoosemans@itg.be 
Keywords: inventory, sampling strategy, biodiversity, invasive species, Culicidae

(Accepted 3 July 2012; First published online 13 September 2012)

\section{Introduction}

In general, the term biodiversity comprises the diversity of species and their complex interplay with the abiotic, nonliving, features of their environment. Biodiversity relates to the range of genes, species and ecosystems and can be divided into a structural, functional and spatial component changing over time and space (Gaston, 1996). Gaining knowledge on these different components of mosquito biodiversity is essential to understand the current risk of new invading species and disease transmission in a region (Manguin \& Boëte, 2011). The structural biodiversity component encompasses species richness based on morphological or molecular characteristics and their relative abundance. The functional aspect comprises the ecology of different species and their habitat preferences, their influence on ecosystem functioning, and the species interactions (e.g. competition, the influence of invasive species). Spatial biodiversity, in turn, covers the occurrence of species in a given region or habitat, which is essential to predict species variance with changing environmental and climatic conditions. Despite the importance of these components in risk assessments, little attention has been paid to the distribution and biodiversity of mosquitoes in northern Europe, except for some scattered studies (Schäfer, 2004). Studies focused mainly on indigenous vector species like Anopheles spp. in southern Europe (Patsoula et al., 2007; Ponçon et al., 2007; Di Luca et al., 2009; Vicente et al., 2011) and invasive (potential vector) species such as Aedes albopictus (=Stegomyia albopicta in the phylogenetic classification of Reinert et al., 2009) and Ae. j. japonicus (also Ochlerotatus j. japonicus or Hulecoeteomyia j. japonicus) (see Medlock et al., 2012) but disregarded information about the spatial distribution of other indigenous (adult) mosquito species. Overall, recent knowledge on the different aspects of biodiversity of both indigenous and invading vector mosquito species is currently missing in many northern European countries, including Belgium. Besides a paper published in 2004 reporting the occurrence of Aedes albopictus in Belgium (Schaffner et al., 2004), only a few publications are available on mosquitoes in Belgium. Some scattered records of mosquito species in Belgium were mentioned by Goetghebuer (1925) in the beginning of the 20th century. In the 1940s, the presence of malarial mosquitoes and associated malaria transmission risk was studied at several locations in Belgium (Rodhain \& van Hoof, 1942, 1943; Rodhain \& Van Mechelen, 1944); and, during the early 1950s, mosquito nuisance was investigated around the city of Antwerp (Wanson, 1952). Although a large collection is present at the Royal Belgian Institute of Natural Sciences (RBINS), the majority of this material was never identified. In 1991, a checklist of Belgian Culicidae was created comprising 24 species present in the RBINS collection and additional species mentioned in card-indexes (Gosseries \& Goddeeris, 1991), based on historical data mainly collected between 1909 and 1958. Moreover, records are sometimes clustered in space and time, as, for example, between 1940 and 1950 mosquitoes were mainly collected around Ghent and Brussels (Dekoninck et al., 2011a). No exotic mosquito species were recorded in this checklist. Acquiring information on the biodiversity of Culicidae is an essential step towards understanding the current risk of diseases transmitted by mosquitoes and preparing for future threats. In that framework, a national inventory started in 2007 (MODIRISK, www.modirisk. be). It was based on a specific and unique sampling strategy designed to allow a rapid overview of the Belgium Culicidae.

This paper, therefore, elaborately describes the applied sampling protocol, as it was specifically developed for this study. Furthermore, our aims were (i) to update the current knowledge on mosquito species present in Belgium, (ii) to assess structural biodiversity based on different species richness indices and (iii) assess spatial biodiversity according to the main environmental types.

\section{Material and methods \\ Sampling design}

Cross-sectional field surveys were conducted using the Corine (2000) Land Cover classification (NGI, 2004), delineating potential mosquito habitats. The Corine Land Cover Classes were regrouped in six classes: (i) urban biotopes, (ii) land in agricultural cycle, (iii) natural terrestrial environmental type, (iv) mosquito specific areas (ports, airports, dump sites, moors and heat land, inland marshes, salt marshes), (v) secondary sites (industrial and commercial units, roads, mines and mineral extraction sites, construction sites) and (vi) water bodies. The last two were not included in the inventory. The first three were retained for a random selection of sampling sites and were renamed as (i) urban, (ii) rural and (iii) natural. A fourth class was additionally defined as selected sites, those prone to an introduction of vectors or pathogens, subdivided into import risk areas industry (IRA-industry) and importation risk areas (IRA). The former included used tire importation/storage companies, bamboo importers, harbours and airports and are mainly areas at risk for importation of exotic mosquito species. The IRA included zoos, safari parks, protected areas involving presence of large numbers of migratory birds where importation of pathogens is possible. This data layer was then overlaid with the Military Grid Reference System (MGRS) (Hagemeir \& Blair, 1997), which is an extension of the UTM system. A total of $31210 \times 10 \mathrm{~km}$ MGRS cells are identified across Belgium. The aim was to sample per cell an average of three representative environmental types, representing a total of 936 sampling points. The number of points assigned for each Corine land cover aggregated class was proportional to its total surface in Belgium, and each point received a random set of $X$ and $Y$ coordinates. Given the random location, each point was assigned to a full address, i.e. street, house number and postal code using the geocoding functionality from ArcView3.2 and based on the geocoding street network data layer (TeleAtlas MultiStreetNet). Each point was initially linked to the nearest street segment (i.e. a segment of a street between cross roads) using a spatial join. 
Table 1. Taxonomic diversity (Simpson index, 1-D; Shannon-Wiener diversity, H'; Shannon-Wiener Evenness, E') by main Corine habitat type.

\begin{tabular}{|c|c|c|c|c|c|}
\hline & \multicolumn{5}{|c|}{ Habitat } \\
\hline & Urban & Rural & Nature & IRA_nature & IRA_industry \\
\hline Number of sites sampled & 171 & 577 & 184 & 37 & 26 \\
\hline Total of specimens collected & 3992 & 12100 & 2553 & 6857 & 1031 \\
\hline Mean number of specimens per trap & 23.4 & 21.0 & 13.9 & 185.3 & 38.2 \\
\hline Simpson Index & 0.476 & 0.299 & 0.765 & 0.605 & 0.099 \\
\hline Shannon-Wiener diversity & 1.107 & 0.830 & 1.951 & 1.354 & 0.274 \\
\hline
\end{tabular}

Table 2. The total number of specimens collected per species and the number of study sites where the species were caught.

\begin{tabular}{|c|c|c|c|c|}
\hline Species & Abbreviation & $\begin{array}{l}\text { Total number of specimens } \\
\text { collected (\% of total) }\end{array}$ & $\begin{array}{c}\text { Number of sites where the species } \\
\text { was found ( } \% \text { of all sites) }\end{array}$ & Environmental type \\
\hline Ae. annulipes & Aeanni & $42(0.16)$ & $8(0.80)$ & $\begin{array}{l}\text { rural, natural and } \\
\text { IRA_natural }\end{array}$ \\
\hline Ae. caspius & Aecasp & $80(0.30)$ & $12(1.20)$ & $\begin{array}{l}\text { urban, rural and } \\
\text { IRA_natural }\end{array}$ \\
\hline $\begin{array}{l}\text { Ae. cinereus/ } \\
\text { geminus }\end{array}$ & Aecine & $1338(5.04)$ & $74(7.41)$ & all \\
\hline Ae. geniculatus & Aegeni & $164(0.62)$ & $48(4.81)$ & All \\
\hline Ae.j.japonicus * & Aejapo & $3(0.01)$ & $1(0.10)$ & IRA_industry \\
\hline Ae. koreicus * & Aekore & $6(0.02)$ & $2(0.20)$ & natural \\
\hline Ae.punctor & Aepunc & $531(2.00)$ & $65(6.51)$ & All \\
\hline Ae. rusticus & Aerust & $178(0.67)$ & $33(3.30)$ & $\begin{array}{l}\text { urban, rural, natural and } \\
\text { IRA_natural }\end{array}$ \\
\hline An. maculipennis & Anmacu & $43(0.16)$ & $23(2.3)$ & $\begin{array}{l}\text { urban, rural, natural and } \\
\text { IRA_natural }\end{array}$ \\
\hline An. messeae & & $24(0.09)$ & $13(1.3)$ & $\begin{array}{l}\text { urban, rural, natural and } \\
\text { IRA_natural }\end{array}$ \\
\hline An. plumbeus & Anplum & $391(1.47)$ & $114(11.41)$ & All \\
\hline Anopheles claviger & Anclav & $935(3.52)$ & $185(18.52)$ & All \\
\hline $\begin{array}{l}\text { Coquillettidia } \\
\text { richiardii }\end{array}$ & Cqrich & $4095(15.43)$ & $38(3.80)$ & All \\
\hline Cs morsitans & Csmors & $92(0.35)$ & $17(1.70)$ & $\begin{array}{l}\text { rural, natural and } \\
\text { IRA_natural }\end{array}$ \\
\hline Culex pipiens & Cxpipi & $16,349(61.62)$ & $698(69.87)$ & All \\
\hline Culiseta annulata & Csanna & $577(2.17)$ & $162(16.22)$ & All \\
\hline$C x$ territans & Cxterr & $11(0.04)$ & $7(0.70)$ & $\begin{array}{l}\text { rural, natural and } \\
\text { IRA_natural }\end{array}$ \\
\hline
\end{tabular}

* exotic species.

\section{Sampling trap}

The $\mathrm{CO}_{2}$ baited trap Mosquito Magnet Liberty Plus (Woodstream Corp., Lititz, PA, USA) was used throughout Belgium for mosquito sampling. This trap is a $\mathrm{CO}_{2}$-baited trap which outperformed both in number of specimens and number of genera collected compared to seven other trap systems (Dennett et al., 2004). Furthermore it is the only available trap type that allows the autonomy needed for the trapping scheme. This trap works on a counter flow technique, in which one fan exhausts $\mathrm{CO}_{2}$, heat and moisture from the bottom outlet, while the other fan draws air from the bottom inlet and forces it out at the top, causing a suction that pulls mosquitoes into a net.

\section{Sampling frequency}

Mosquitoes were sampled from May till October in 2007 and 2008 according to the sampling design explained above. Each year, the entire country was sampled twice to counteract possible seasonal influences in each region. The first sampling 

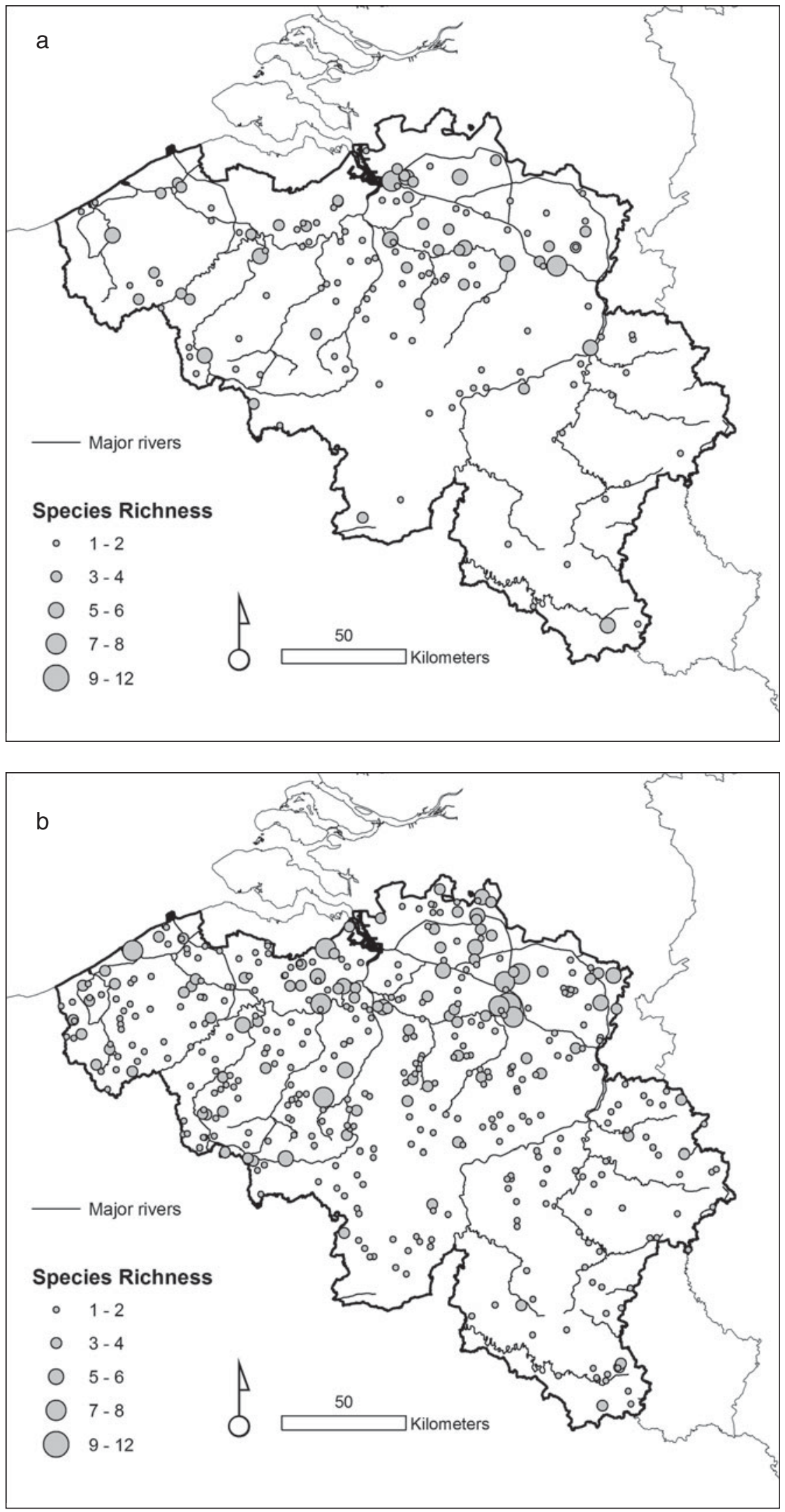

Fig. 1. For Figure legend see opposite page. 

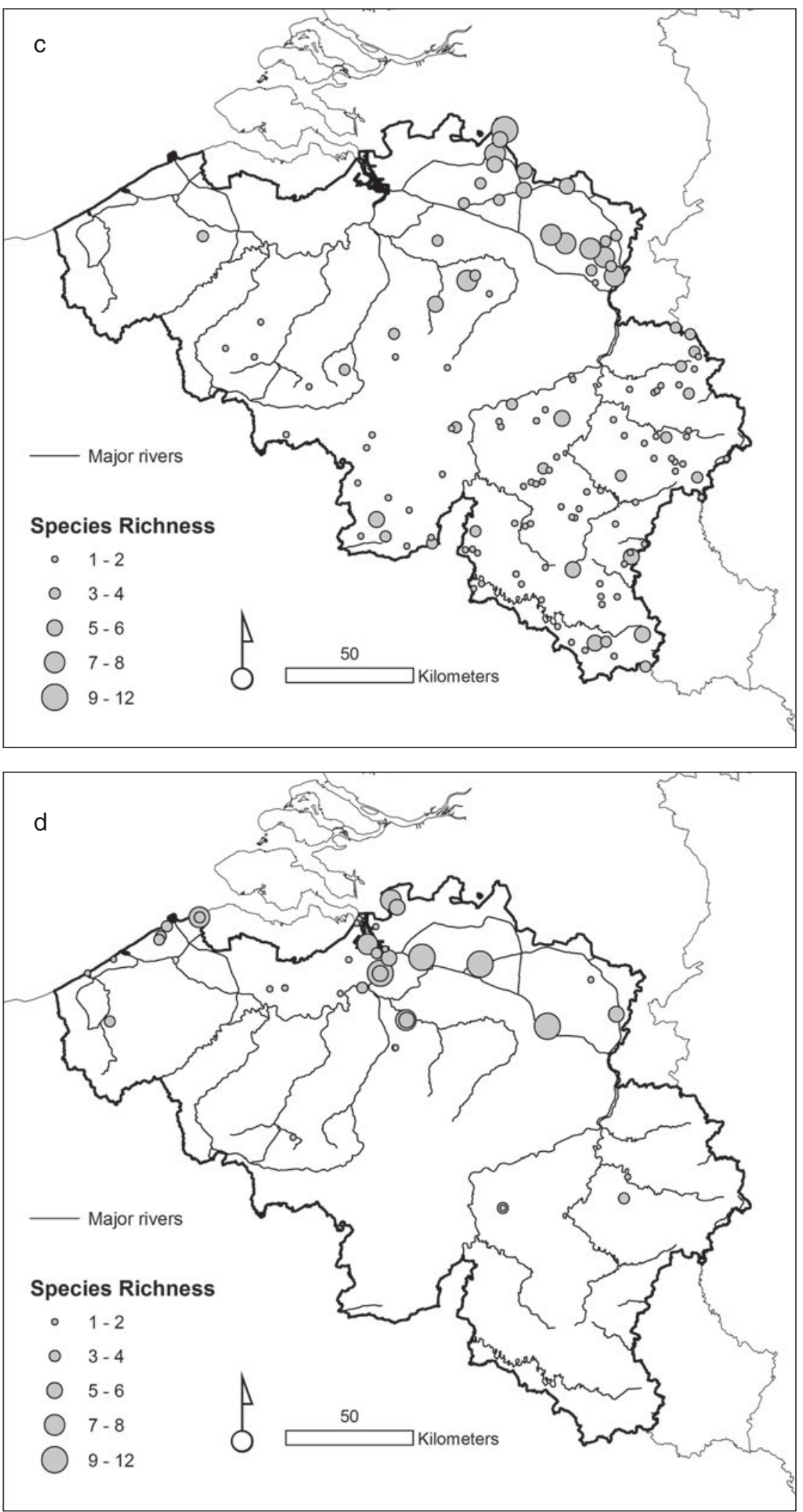

Fig. 1. (a) Observed species richness in the environmental type sampled (urban). (b) Observed species richness in the environmental type sampled (rural). (c) Observed species richness in the sampled natural environments. (d) Observed species richness in the import risk areas (natural and industrial sites combined). 
period extended from May till mid-July, the second from the end of July till the beginning of October. Within each delineated MGRS cell, sampling points were randomly allocated to season and year. Although each site was only visited once, nearby sites were sampled during every period and year giving a good overview of mosquito presence in a specific area. During the inventory campaign, 27 traps operated simultaneously. Each trap operated seven days in one study site after which it was placed on the next study site. Field work was done on Monday, Tuesday and Wednesday; each day three traps were emptied and replaced per field team (nine in total). The organization of the field work and the morphological identification of the mosquitoes were done on the other days. Each field team had a personal digital assistant (PDA) and global positioning system (GPS) to their disposal to easily locate the selected sites, record the exact GPS position of the traps and to record additional field information such as the presence or absence and artificial, natural, permanent and temporal types of habitats.

\section{Morphological and molecular identification}

Morphological identification was done using the electronic identification key of Schaffner et al. (2001) and the printed keys of Schaffner (1993) and Becker et al. (2010). Afterwards, data were stored in a specially designed web-based database. To assure quality of morphological identifications, a random sample (10\%) of the identified mosquitoes was re-identified by an external expert (F. Schaffner). Voucher specimens were deposited at the Royal Belgian Institute of Natural Science. There is a growing acceptance of at least the recognition of Ochlerotatus as a distinct genus and recent publications (Reinert, 2000; Reinert et al., 2004, 2008a, b, 2009; Shepard et al., 2006) indicate justified reasons for the reclassification of the genus Aedes (especially elevating Ochlerotatus to generic rank). Recent changes to the classification of the composite genus, including the further division of the genera Aedes and Ochlerotatus have led to much confusion for non-taxonomists interested in potential vector mosquito species. For this reason, we prefer to maintain in this paper the traditional classification (pre-Reinert, 2000).

Members of the Anopheles maculipennis complex were identified to species level using a specifically designed PCRRFLP method (Nicolescu et al., 2004) that targets the internal transcribed spacer 2 (ITS2) region. DNA extraction was performed using the protocol described by Collins et al. (1987) after which the ITS2 region was amplified using primers described by Collins \& Paskewitz (1996). Consequently, the positive amplification products were digested using CfoI restriction enzyme (Roche Molecular Biochemicals Ltd, Sussex, UK) (Nicolescu et al., 2004). Restriction fragments were visualised on a $3 \%$ agarose gel. The PCR-RFLP does not differentiate between Anopheles messeae and the recently described and closely related $A n$. daciae (Nicolescu et al., 2004), and thus all specimens with a shared RFLP pattern were sequenced (Genoscreen, Lille, France) and compared with Genbank sequences. Additionally, a selected number (five of each species) of positive ITS2 PCR amplifications were sent for sequencing (Genoscreen, Lille, France).

\section{Data analysis}

Alpha diversity (as defined by Whittaker, 1972) in predefined habitat types was calculated using three different indices (Simpson and Shannon species richness indexes and species abundances through rarefaction), taking into account the number of sites sampled per habitat type. Simpson's index of diversity, $\left(1-\mathrm{D}=1-\Sigma\left[n_{\mathrm{i}} \times\left(n_{\mathrm{i}}-1\right) / N \times(N-1)\right]\right.$, where $n_{\mathrm{i}}$ is number of the $i$-th species and $N$ is the number of individuals in the studied Corine habitat), is a measurement of the probability that two randomly selected individuals in an area belong to a different species. The closer $1-\mathrm{D}$ is to one, the more diverse the habitat is. Shannon-Wiener index $\left(H^{\prime}=-\Sigma p_{i} \times \ln p_{i}\right)$, where $p_{i}$ is the proportion of the $i$-th species in the studied habitat) was used as a measure of community heterogeneity (Krebs, 1989). Shannon evenness $\left(E^{\prime \prime}=S / \ln \left(H^{\prime \prime}\right)\right.$, where $S$ is the total number of species calculates how individuals are distributed among species per habitat. Rarefaction based estimates were calculated using EcoSim (Gotelli \& Entsminger, 2001) to estimate and compare the relative abundance and the density of mosquito species among environmental types, and thus test trapping scheme efficiency. The use of rarefaction allows comparison of the number of species in samples of different sizes as rarefaction simulates the expected number of species at a given number of individuals sampled, typically that of the smallest unit. In this paper, the sampling unit is the habitat type. It indicates how many species can be expected for a given sampling effort. Rarefaction curves generally grow rapidly at first, as the most common species are found, but level-off as only the rarest species remain to be sampled. Individual-based rarefaction curves were created in GraphPad Prism version 5.0 for Windows (GraphPad Software Inc.).

The Kruskal-Wallis one-way analysis of variance was used to test whether there is a difference in sampling results between seasons and years.

A canonical analysis (CA) was carried out to preliminary explore variation in assemblages of Culicidae between the defined habitat types. This analysis was performed using the CA package in R 2.13.0. (Greenacre \& Nenadic, 2011). All species were included regardless of whether they are rare or common; absolute values were used as described by Jongman et al. (1995) and Legendre \& Legendre (1998). Specimens belonging to the Anopheles maculipennis complex were included as such without taking the results of the PCR-RFLP into account, mainly due to the fact that not all individuals could be included in the molecular analysis.

\section{Results}

Based on the sampling strategy described above, 936 sites were randomly identified in three key habitats (urban, rural and natural); $97 \%$ of these were effectively sampled and mosquitoes were collected in $78 \%$ of the sites. Additionally, 45 importation risk areas were included in the inventory, of which 27 sites were located in natural areas (IRA, total of 37 traps) and 18 at industrial companies (IRA-industry, total 24 traps). Table 1 summarizes the actual number of sites sampled in each category.

\section{Species diversity}

A total of 26,533 individuals, morphologically belonging to 22 species and five traditionally recognized genera, were 
collected and identified (table 2). Because individuals of Ae. geminus closely resemble those of Aedes cinereus, and identification can only be done with certainty through characters of the male genitalia, individuals were not further differentiated. The most species-rich genus in Belgium was Aedes, whereas Coquillettidia was only represented by one species. The five most abundant species were Culex pipiens (61.62\%), Coquillettidia richiardii $(15.43 \%)$, Ae. cinereus or Ae. geminus (5.04\%), An. claviger (3.52\%) and Ae. vexans (2.93\%). The high abundance of $C q$. richiardii is, however, due to one study site, a nature reserve in the harbour of Antwerp, where more than 3700 specimens of this species were collected. The species was caught in 38 study sites. Eighty individuals of An. maculipennis s.l. were collected, of which 67 were molecularly identified. Forty-three individuals belonged to Anopheles maculipennis s.s. (64.18\%) and 24 to An. messeae. Both species were collected in higher numbers in the northern part of Belgium, in six sites they occurred sympatrically, and in 24 other sites either one of them occurred (seven sites positive for $A n$. messeae, 17 for An. maculipennis s.s.). Positive ITS2 amplifications of An. messeae s.l. were sequenced but no clear separation between $A n$. messeae and An. daciae could be observed. Combining morphological and molecular identification, a total of 23 species were collected during the inventory. Four species were collected in more than 100 study sites (table 2): An. claviger (18.52\% of the sites), An. plumbeus (11.41\%), Culiseta annulata (16.22\%) and Culex pipiens $(69.87 \%)$. Two exotic mosquito species were collected from two distinctive sites; Ae .j. japonicus from a used tyre trade near Namur and Ae. koreicus from a randomly selected site near Maasmechelen. All mosquito species were found in both years, although the abundance of these varied between years and seasons. Despite the fact that most species have a different phenology and are often characterized as 'early' or 'late' season species, the species composition was not significantly different between years and between seasons tested within each year (Kruskal-Wallis test, $\mathrm{df}=1, P>0.05$ ).

\section{Species abundances and richness}

The taxonomic diversity differed among the natural, rural, urban and importation-risk environments (fig. 1a-d). Most species (21) were caught in the IRA sites (4\% of the study sites) followed by rural (56\% of the study sites), and natural environmental types ( $20 \%$ of the study sites) where 20 species were collected (table 1). Species diversity $\left(\mathrm{H}^{\prime \prime}+\right.$ Simpson) and evenness $\left(E^{\prime \prime}\right)$ were both higher in natural and IRA sites than in others (table 1). Individual based rarefaction curves suggest that, for equal sample size, expected species richness in rural environmental types is slightly lower than in other environmental types with higher species richness values (fig. 2). Moreover, the curve of the rural sites is still asymptotic, predicting an increment of species with higher sampling effort. Lowest species richness was observed in IRA-industry sites, and the rarefaction curve of this latter environmental site only reached a plateau at higher calculated abundances. According to this analysis, overall species accumulation is expected to increase with a higher sampling effort in this environmental type.

The CA ordination (fig. 3) shows an incipient separation between a cluster of urban/rural/IRA- industry sites, natural and IRA sites. Axis one explains $62 \%$ (eigenvalues $=0.57$ ) and axis two $26 \%$ (eigenvalues $=0.24$ ) of the observed variance. Four clusters can be distinguished: one related to the

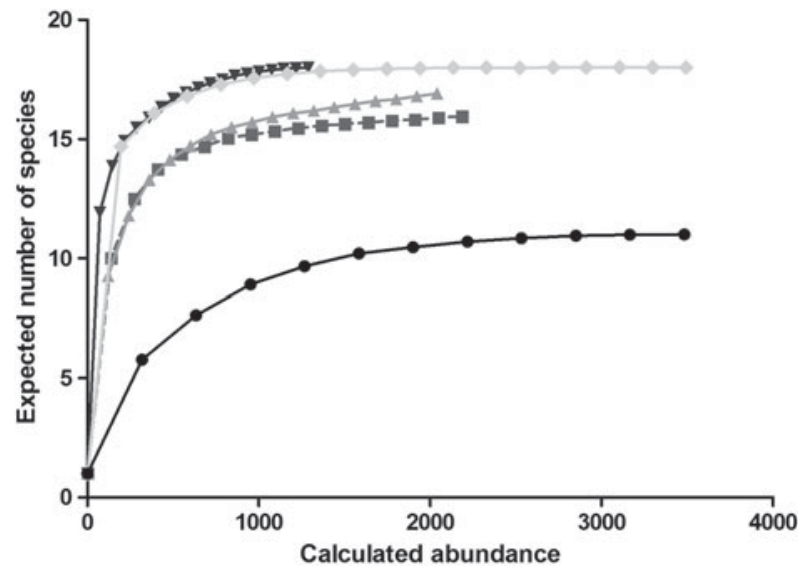

Fig. 2. Species accumulation curve using the rarefaction method where the expected species richness and its standard deviation are obtained by sampling individuals based on their corrected abundance per habitat. $\rightarrow-=$, Urban; $\rightarrow-$, Rural; $\rightarrow$, Nature; $\longrightarrow$, IRA_nature; - - IRA_industry.

urban/rural/IRA industry group with $C x$. pipiens, Ae. caspius, Ae.j japonicus and Ae.vexans, Cs. annulata and An. maculipennis and An. claviger. Secondly, a large group of species is distinguished that could not be allocated to a specific habitat type, including the now widely distributed An. plumbeus. A third group is discriminated, including Cq. richiardii and Ae. detritus, commonly found in IRA sites. And finally, a fourth cluster can be observed with forest species like Ae. communis, Ae. geniculatus, Ae. punctor and Cs. morsitans, as well as the exotic Ae. koreicus, are more readily found in sites characterized as natural.

\section{Discussion}

The structural biodiversity in Belgium was assessed through (i) morphological and molecular identification of the species, (ii) three different diversity indexes (Simpson richness, Shannon richness and evenness) and (iii) rarefaction analyses based on the pre-defined habitat types. The current inventory MODI RISK reported a total of 23 species (including two exotic species for Belgium) based on two years of intensive sampling in 971 sites scattered over Belgium. Rarefaction curves indicate that the expected number of species present was indeed sampled in almost all main environmental types. Thus, further sampling would probably not increase the observed number of species, indicating the sampling scheme worked well. Moreover, two exotic species were collected, one in a manually selected importation risk site (Ae. j. japonicus in Natoye, Namur) and one (Ae. koreicus in Maasmechelen, Limburg) from a randomly chosen site (Versteirt et al., 2009, 2012), amply demonstrating the effectiveness of the sampling.

Prior to these outcomes, a checklist of Belgian Culicidae listing 24 species was published by Gosseries \& Goddeeris (1991) based on historical data mainly collected between 1909 and 1958. In addition, Schaffner et al. (2001) listed a total of 26 species expected in Belgium based on literature data. Recent publications of Versteirt et al. (2009) and Dekoninck et al. (2011a) resulted in a total of 30 confirmed species. Eight species, recorded at least once in Belgium, were not found during the current study, namely Ae. albopictus, Ae. dorsalis, 


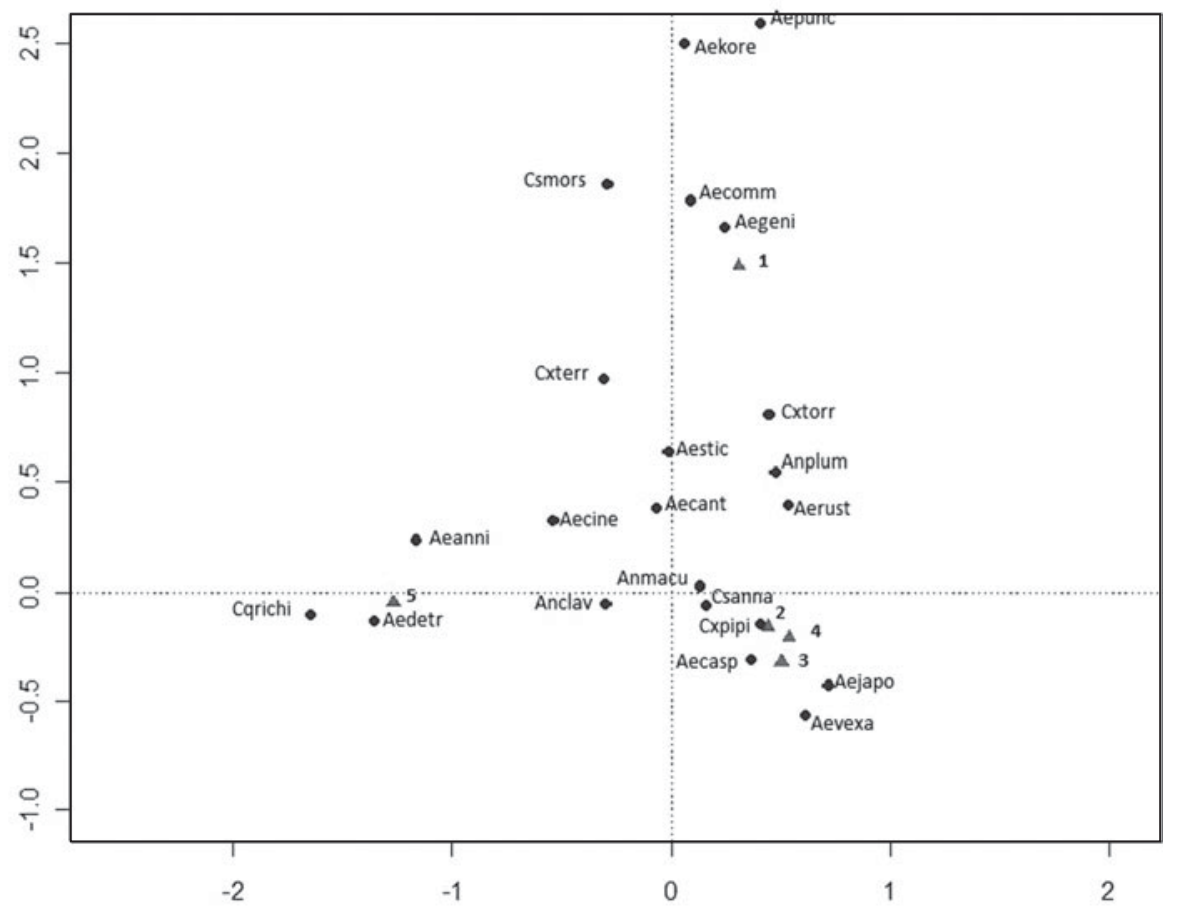

Fig. 3. Canonical analyses biplot of the mosquito fauna in Belgium with species located where they are most abundant. A total of four distinct clusters can be observed: natural sites (1) and species, IRA (5) sites and species, urban(2)/rural(3)/IRA-industry(4) sites and species and a group including species with a wider distribution range. Species abbreviations can be found in table 2 .

Ae. flavescens, An. atroparvus, Cx. hortensis, Cs. ochroptera, Cs. subochrea and Cs. fumipennis (Gosseries \& Goddeeris, 1991; Schaffner et al., 2004). Missing species can be mainly linked to specific environmental types and mosquito feeding habits. Aedes dorsalis, Ae. flavescens and An. atroparvus are mainly associated to brackish environments, a habitat type that has become very scarce in Belgium since the destruction of brackish wetlands in the 1950s (Perillo et al., 2009). Moreover, due to competition with the more ubiquitous species An. messeae, An. atroparous has become very rare (Knottnerus, 2002). Culex hortensis is frequently found in the Mediterranean region, elsewhere it is rather rare and occurs only sporadically in detectable numbers (Becker et al., 2010). Culiseta ochroptera and Cs. subochrea are very rare in western and central Europe and are, thus, only scarcely reported (Becker et al., 2010). The absence of Cs. fumipennis during the inventory is difficult to explain since it is widely distributed throughout Europe. This species was, however, caught in 2010 during a revisit to some of the 971 sites (unpublished data). Pollution of its main habitat, i.e. open sunlit shallow temporary pools with rich vegetation or covered with duckweed (Lemna sp.) (Becker et al., 2010), seems a likely explanation for this absence. Aedes albopictus was detected in 2000 in Vrasene (Schaffner et al., 2004) in a company importing second-hand tires. The species was not found again during subsequent surveillance visits. It seems that it was naturally eliminated and up to date not reintroduced. Although trap choice could influence the number of specimens and even species caught, $\mathrm{CO}_{2}$-baited traps are efficient in sampling most or all species present in a given area (Petric et al., 1999; Hoel et al., 2009; Coosemans et al. 2011). Compared to Belgium, with 23 detected species during this inventory, 65 species are present in France, 15 in Luxembourg, 27 in the Netherlands, 34 in the UK (Snow et al., 1997; Schaffner, 1999; Schaffner et al., 2001; Medlock \& Vaux, 2009). However, it should be noted that, especially in France and the UK, a greater diversity in habitat types and eco-regions exists, offering a higher variety of suitable niches for mosquitoes with a different ecology.

Two members of the An. maculipennis complex were distinguished, namely An. maculipennis and An. messeae. In 2004, a new member of the An. maculipennis complex, viz. An. daciae, was described from Romania (Niclosecu et al., 2004) and was also reported from the UK (Linton et al., 2005). Anopheles daciae was described as a different species of An. messeae based on egg and larval morphology and on their unique ITS2 sequence. However, none of the ITS2 sequences obtained in this study showed $100 \%$ similarity with $A n$. messeae or $A n$. daciae present in Genbank and BOLD. Moreover, intraspecific and intra-individual ITS2 variants in An. messeae was recently shown (Bezzhonova \& Coryacheva, 2008), and they correspond with variants that were used to differentiate An. messeae and $A n$. daciae. These findings indicate that the ITS2 cannot distinguish these two species.

Spatial biodiversity to assess the relationship between the pre-defined habitat types and the species occurrence was estimated by CA technique. The analysis shows a clear separation of the natural, IRA and urban/rural/IRA sites, with (mostly) typical species allocated to the different clusters. The presence of Ae. caspius, Ae. vexans, An. maculipennis and An. claviger in the urban/rural/IRA-industry group indicates, however, the fragmented landscape of Belgium, where urban and rural areas are connected to (semi-)natural sites. Currently, a worldwide trend to construct, restore and protect wetlands emerged which will create a suitable habitat in 
Table 3. Overview of the found species during the MODIRISK inventory, with information on their vectorial capacity.

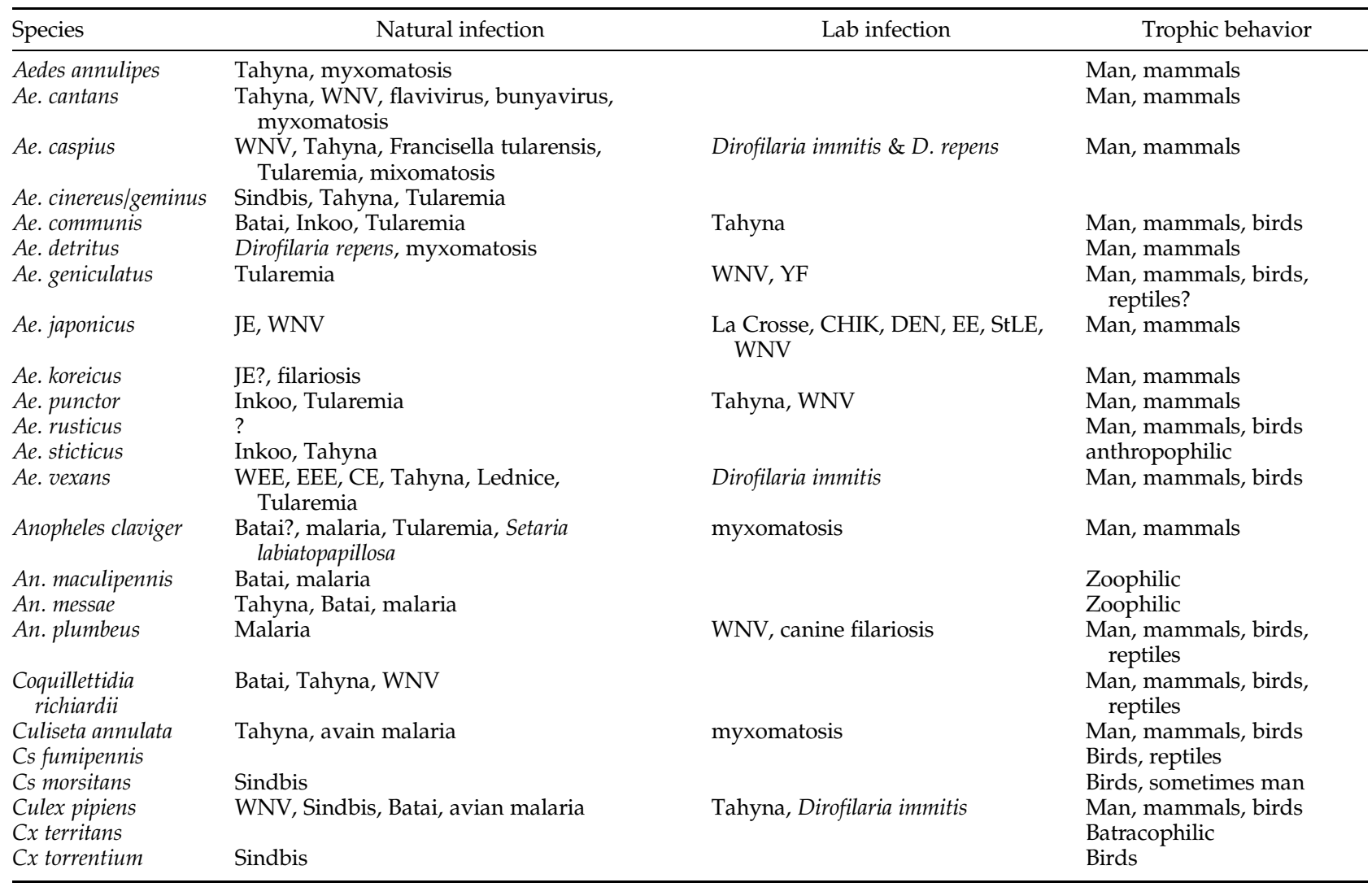

WEE, Western Equine Encephalitis; EEE, Eastern Equine Encephalitis; CE, California Encephalitis group; WNV, West Nile Virus; JE, Japanese Encephalitis; StLE, Saint Louis Encephalitis; YF, Yellow Fever (adapted from Becker et al., 2010).

which host, vectors and pathogens can come into contact, and they might also be prone to pathogen introductions (Dale \& Knight, 2008). These areas, including wetlands, marshes and tidal zones, which were categorized here as IRA and often situated near urbanized areas (like harbors), pose new hazards for the introduction and establishment of vectors and pathogen, and increase the risk of transmission and outbreaks. The urban/rural/IRA-industry cluster seems to be characterized by two species, Ae. caspius and Cx. pipiens, that can cause biting nuisance and are potential vector species of West Nile virus, Tahyna virus, Sindbis virus and Dirofilaria immitis amongst others (Becker et al., 2010). Species having a centralized position in the CA biplot are those with a more even distribution over the different environmental types. For example, An. plumbeus has recently adapted to man-made artificial breeding sites and is undergoing a highly expanding distribution in Belgium (Dekoninck et al., 2011b).

The inventory done in the framework of the MODI RISK project was based on a random (statistical) approach. Such a sampling scheme has some drawbacks, such as the one weekone site trapping scheme, the use of one trapping device and entailing that areas or specific habitats may have been insufficiently sampled or sampled during the wrong season (e.g. Cs. fumipennis habitats). However, comparing the number of found and expected species, it can be concluded that this inventory approach was successful, emphasizing its utility. One of the major advantages is certainly the fact that no prior knowledge was required and that there was no biased choice of sampling sites. Moreover, the entire country could be sampled over different years and periods. The acquired knowledge on species presence and distribution in Belgium can be used to develop mosquito species distribution models and to assess the actual countrywide transmission risk of mosquito-borne diseases, taking into account that several ecological, biological and socio-economic factors can interfere. Based upon their ecology and biting preference, several species present in Belgium are potential vectors of pathogens, such as West Nile virus, avian malaria, Usutu, Tahyna or Sindbis virus (Becker et al., 2010) (see table 3). The simultaneous temporal and spatial presence of competent vector and hosts is the first condition for arboviral transmission; however, other factors, such as their distribution and the correct combination of environmental conditions, are essential for successful and persistent transmissions (Randolph \& Rogers, 2010). Indeed, the most important epidemiological parameters for risk assessments include vector diversity, spatial and temporal variation in vector abundance and pathogen prevalence in the vector population (Braks et al., 2011). This knowledge is, however, lacking in most European countries (Braks et al., 2011). An initiative was started to overcome this information gap by bringing entomological and public health expertise together in a European network (VBORNET). In conclusion, the present study reports a country-wide mosquito inventory with emphasis on species 
richness, distribution and occurrence in the main environmental types, which is a first step toward risk assessment of mosquito-borne diseases. To keep this inventory up to date will be challenging but is highly desirable given the potential risk of mosquito-borne diseases in Europe and of changing species distributions due to climate change.

\section{Acknowledgements}

We would like to thank all people involved during the sampling (inventory and validation), private owners, companies, conservators of nature reserves and other authorities (commune, region). Many thanks to Annemie Van Ranst, Bram Wellekens, Cleo Pandelaers, Rien Dekeyzer, Marijke Wouters, Stefan Kerkhof and Charlotte Sohier without whom the field work would not been done so smoothly. We especially want to express our gratitude to Patricia Roelants and Leen Denis for assistance in (and outside) the lab. We thank FS for the technical support and the quality control of the morphological identifications. This work was funded by the Belgian Science Policy Programs (Belspo, SD/BD/04A and $\mathrm{SD} / \mathrm{BD} / 04 \mathrm{~B})$.

\section{References}

Becker, N., Petric, D., Zgomba, M., Boase, C., Dahl, C., Madon, M. \& Kaiser, A. (2010) Mosquitoes and their Control. New York, USA, Kluwer Academic/Plenum.

Bezzhonova, O.V. \& Coryacheva, I.I. (2008) Intragenomic heterogeneity of rDNA internal transcribed spacer 2 in Anopheles messeae (Diptera: Culicidae). Journal of Medical Entomology 45, 337-341.

Braks, M., van der Giessen, J., Kretzschmar, M., van Pelt, W., Scholte, E.-J., Reusken, C., Zeller, H., Van Bortel, W. \& Sprong, H. (2011) Towards an integrated approach in surveillance of vector-borne diseases in Europe. Parasites $\mathcal{E}$ Vectors 4, 192.

Collins, F.H. \& Paskewitz, S.M. (1996) A review of the use of ribosomal DNA (rDNA) to differentiate among cryptic Anopheles species. Insect Molecular Biology 5, 1-9.

Collins, F.H., Mendez, M.A., Rasmussen, M.O., Mehaffey, P.C., Besansky, N.J. \& Finnerty, V. (1987) A ribosomal RNA gene probe differentiates member species of the Anopheles gambiae complex. American Journal of Tropical Medicine and Hygiene 37, 37-41.

Coosemans, M., Hendrickx, G., Grootaert, P., Hance, T., Versteirt, V. \& Van Bortel, W. (2011) Mosquito vectors of disease: spatial biodiversity, drivers of change, and risk. Final Report. Brussels: Belgian Science Policy 2009. Research Programme Science for a Sustainable Development.

Dale, P.E.R. \& Knight, J.M. (2008) Wetlands and mosquitoes: a review. Wetlands Ecology and Management 16, 255-276.

Dekoninck, W., De Keyser, R., Hendrickx, F., Kerkhof, S., Van Bortel, W., Versteirt, V. \& Grootaert, P. (2011a) Mosquito (Culicidae) voucher specimens in the RBINS collection: remnants of a past glory or hidden treasure. European Mosquito Bulletin 29, 13-21.

Dekoninck, W., Hendrickx, F., Van Bortel, W., Versteirt, V., Coosemans, M., Damiens, D., Hance, T., De Clercq, E.M., Hendrickx, G., Schaffner, F. \& Grootaert, P. (2011b) Human induced expanded distribution of Anopheles plumbeus, experimental vector of West Nile virus and a potential vector of human malaria in Belgium. Journal of Medical Entomology 48, 924-928.
Dennett, J.A., Vessey, N.Y. \& Parsons, R.E. (2004) A comparison of seven traps used for collection of Aedes albopictus and Aedes aegypti originating from a large tire repository in Harris County (Houston), Texas. Journal of the American Mosquito Control Association 20, 342-349.

Di Luca, M., Boccolini, D., Toma, L., Mancini Barbieri, F., Massa, A. \& Romi, R. (2009) A 2-year entomological study of potential malaria vectors in Central Italy. Vector-Borne and Zoonotic Diseases 9, 703-711.

Gaston, K.J. (1996) What is biodiversity? pp. 1-9 in Gaston, K.J. (Ed.) Biodiversity: A Biology of Numbers and Difference. Oxford, UK, Blackwell Science Ltd.

Goetghebuer, M. (1925) Catalogue raisonné des Culicidés de Belgique. Bulletin et Annales de la Société Entomologique de Belgique 65, 209-219.

Gosseries, J. \& Goddeeris, B. (1991) Culicidae partim 70. 338 pp in Grootaert, P., De Bruyn, L. \& De Meyer, M. (Eds) Catalogue of the Diptera of Belgium. Brussels, Belgium, Studiedocumenten KBIN, Documents de travail de l"IRScNB.

Gotelli, N.J. \& Entsminger, G.L. (2001) EcoSim: null models software for ecology. Version 7. Acquired Intelligence Inc. \& Kesey-Bear. Jericho, VT 05465. Available online at http:// garyentsminger.com/ecosim.htm (accessed December 2011)

Greenacre, O. \& Nenadic, O. (2011) Package 'ca'. Available online at http://www.carme-n.org (accessed December 2011)

Hagemeijer, E.J.M. \& Blair, M.J. (1997) The EBCC Atlas of European Breeding Birds: Their Distribution and Abundance. London, UK, T \& A.D. Poyser.

Hoel, D.F., Kline, D.L. \& Allan, S.A. (2009) Evaluation of six mosquito traps for collection of Aedes albopictus and associated mosquito species in a suburban setting in north central Florida. Journal of the American Mosquito Control Association 25, 47-57.

Jongman, R.H.G., ter Braak, C.J.F. \& van Tongeren, O.F.R. (1995) Data Analysis in Community and Landscape Ecology. Cambridge, UK, Cambridge University Press.

Knottnerus, O. (2002) Malaria around the North Sea: a survey. pp. 339-353 in Wefer, G., Berger, W.H., Behre, K.-E. \& Jansen, E. (Eds) Climatic Development and History of the North Atlantic Realm: Hanse Conference Report. Berlin, Germany, SpringerVerlag.

Krebs, C.J. (1989) Ecological Methodology. New York, USA, Harper and Row Publishers.

Legendre, P. \& Legendre, L. (1998) Numerical Ecology. 2nd edn. Amsterdam, The Netherlands, Elsevier Science.

Linton, Y.-M., Lee, A.S. \& Curtis, C. (2005) Discovery of a third member of the Maculipennis Group in SW England. European Mosquito Bulletin 19, 5-9.

Manguin, S. \& Boëte, C. (2011) Global impact of mosquito biodiversity, human vector-borne diseases and environmental change. pp 27-50 in Pujol, J.L. (Ed.) The Importance of Biological Interactions in the Study of Biodiversity. Winchester, UK, InTech, Available online at http://www.intechopen.com/ articles/show/title/global-impact-of-mosquito-biodiversityhuman-vector-borne-diseases-and-environmental-change (accessed January 2012).

Medlock, J.M. \& Vaux, A. (2009) Aedes (Aedes) geminus Peus (Diptera, Culicidae) - an addition to the British mosquito fauna. Dipterists Digest 16, 147-150.

Medlock, J.M., Hansford, K.M., Schaffner, F., Versteirt, V., Hendrickx, G., Zeller, H. \& Van Bortel, W. (2012) A review on the invasive mosquitoes of public health concern in Europe: ecology, public health risks, and control options. Vector-Borne and Zoonotic Diseases 12, 435-447. 
Nicolescu, G., Linton, Y.M., Vladimirescu, A., Howard, T.M. \& Harbach, R.E. (2004) Mosquitoes of the Anopheles maculipennis group (Diptera: Culicidae) in Romania, with the discovery and formal recognition of a new species based on molecular and morphological evidence. Bulletin of Entomological Research 94, 525-535.

National Geographic Institute (NGI) (2004) Corine (2000) land cover, Belgium. Available online at http://www.ngi.be/ NL/NL1-5-4.shtm (accessed August 2010).

Patsoula, E., Samanidou-Voyadjoglou, A., Spanakos, G., Kremastinou, J., Nasioulas, G. \& Vakalis, N.C. (2007) Molecular characterization of the Anopheles maculipennis complex during surveillance for the 2004 Olympic Games in Athens. Medical and Veterinary Entomology 21, 36-43.

Perillo, G.M.E., Wolanski, E., Cahoon, D.R. \& Brinson, M.M. (2009) Coastal Wetlands: An Integrated Ecosystem Approach. Amsterdam, The Netherlands, Elsevier.

Petric, D., Zgomba, M., Bellini, R., Veronesi, R., Kaiser, A. \& Becker, N. (1999) Validation of CO2 trap data in three European regions. pp. 437-445 in Proceedings of the $3 \mathrm{rd}$ International Conference of Insect Pests in Urban Environment. Czech University of Agriculture, 19-22 July 1999, Prague, Czech Republic.

Ponçon, N., Toty, C., Ambert, G.L., Le Goff, G., Brengues, C., Schaffner, F. \& Fontenille, D. (2007) Population dynamics of pest mosquitoes and potential malaria and West Nile virus vectors in relation to climatic factors and human activities in the Camargue, France. Medical and Veterinary Entomology 21, 350-357.

Randolph, S.E. \& Rogers, D.J. (2010) The arrival, establishment and spread of exotic diseases: patterns and predictions. Nature Reviews Microbiology 8, 361-371.

Reinert, J.F. (2000) New classification for the composite genus Aedes (Diptera: Culicidae: Aedini), elevation of subgenus Ochlerotatus to generic rank, reclassification of the other subgenera, and notes on certain subgenera and species. Journal of the American Mosquito Control Association 16, 175-188.

Reinert, J.F., Harbach, R.E. \& Kitching, I.J. (2004) Phylogeny and classification of Aedini (Diptera: Culicidae), based on morphological characters of all life stages. Zoological Journal of the Linnean Society 142, 289-368.

Reinert, J.F., Harbach, R.E. \& Kitching, I.J. (2008a) Phylogeny and classification of Finlaya and allied taxa (Diptera: Culicidae: Aedini) based on morphological data from all life stages. Zoological Journal of the Linnean Society 148, 1-101.

Reinert, J.F., Harbach, R.E. \& Kitching, I.J. (2008b) Phylogeny and classification of Ochlerotatus and allied taxa (Diptera: Culicidae: Aedini) based on morphological data from all life stages. Zoological Journal of the Linnean Society 153, 29-114.

Reinert, J.F., Harbach, R.E. \& Kitching, I.J. (2009) Phylogeny and classification of tribe Aedini (Diptera: Culicidae). Zoological Journal of the Linnean Society 157, 700-709.

Rodhain, J. \& van Hoof, M.T. (1942) Recherches sur l'Anophélisme en Belgique. Annales de la Société Belge de Médecine Tropicale-Annalen van de Belgische Vereniging voor Tropische Geneeskunde 21, 19-43.
Rodhain, J. \& van Hoof, M.T. (1943) Recherches sur l'Anophélisme en Belgique (deuxième communication). Annales de la Société Belge de Médecine Tropicale-Annalen van de Belgische Vereniging voor Tropische Geneeskunde 23, 209-218.

Rodhain, J. \& Van Mechelen, J. (1944) Existe-t-il un danger de réapparition du paludisme en Belgique. Annales de la Sociéte Belge de Médecine Tropicale-Annalen van de Belgische Vereniging voor Tropische Geneeskunde 24, 247-261.

Schäfer, M. (2004) Mosquitoes as a part of wetland biodiversity. Comprehensive Summaries of Uppsala Dissertations from the Faculty of Science and Technology 1042. Acta Universitatis Upsaliensis.

Schaffner, F. (1993) Nouvelle clé de détermination pour les imagos femelles du genre Aedes de nord- est de la France. Bulletin de la Société Entomologique de France 98, 29-34.

Schaffner, F. (1999) Biodiversité et dynamique des moustiques de France (Dipetra: Culicidae). Annales de la Société entomologique de France 35, 319-327.

Schaffner, F., Angel, G., Geoffroy, B., Hervy, J.-P., Rhaiem, A. \& Brunhes, J. (2001) The Mosquitoes of Europe: An Identification and Training Programme. Montpellier, France, IRD Editions \& EID Méditerranée.

Schaffner, F., Van Bortel, W. \& Coosemans, M. (2004) First record of Aedes (Stegomyia) albopictus in Belgium. Journal of the American Mosquito Control Association 20, 201-203.

Shepard, J.J., Andreadis, T.G. \& Vossbrinck, C.R. (2006) Molecular phylogeny and evolutionary relationships among mosquitoes (Diptera: Culicidae) from the northeastern United States based on small subunit ribosomal DNA (18S rDNA) sequences. Journal of Medical Entomology 43, 443-454.

Snow, K.R., Rees, A.T. \& Brooks, J.A.H. (1997) A revised bibliography of the mosquitoes of the British Isles. An occasional publication of the British Mosquito Group. London, UK, University of East London Press.

Versteirt, V., Schaffner, F., Garros, C., Dekoninck, W., Coosemans, M. \& Van Bortel, W. (2009) Introduction and Establishment of the Exotic Mosquito Species Aedes japonicus japonicus (Diptera: Culicidae) in Belgium. Journal of Medical Entomology 46, 1464-1467.

Versteirt, V., Pecor, J.M., Fonseca, D., Coosemans, M. \& Van Bortel, W. (2012) Confirmation of Aedes koreicus (Diptera: Culicidae) in Belgium and description of morphological differences between Korean and Belgian specimens validated by molecular identification. Zootaxa 3191, 21-32.

Vicente, J.L., Sousa, C.A., Alten, B., Caglar, S.S., Falcuta, E., Latorre, J.M., Toty, C., Barré, H., Demirci, B., Di Luca, M., Toma, L., Alves, R., Salgueiro, P., Silva, T.L., Bargues, M.D., Mas-Coma, S., Boccolini, D., Romi, R., Nicolescu, G., do Rosario, V.E., Ozer, N., Fontenille, D. \& Pinto, J. (2011) Genetic and phenotypic variation of the malaria vector Anopheles atroparous in southern Europe. Malaria Journal 10, doi:1 0.1186/1475-2875-10-5.

Wanson, M. (1952) Le problème des moustiques anversois. Annales de la Société Royale Zoologique de Belgique 83, 339-369.

Whittaker, R.H. (1972) Evolution and measurement of species diversity. Taxon 21, 213-251. 